\title{
Penerapan Konsep Kesehatan dan Keselamatan Kerja \\ di Rumah Sakit oleh Perawat \\ Lili Evalina \\ lili.evalina@gmail.com
}

\section{LatarBelakang}

Rumah Sakit menurut World Health Organization (2015) merupakan asset penting bagi masyarakat yang termasuk ke dalam bagian dari kesatuan organisasi sosial dan kesehatan, dimana pelayanan yang diberikan disesuaikan dengan jenis intervensi yang diberikan dalam sistem dan pelayanan kesehatan serta pendidikan. Sehingga dalam hal ini diperlukan kualitas pelayanan yang baik dalam memberikan pelayanan kepada masyarakat. Pemberian pelayanan yang berkualitas dapat menimbulkan juga potensi bahaya di rumah sakit. Potensi bahaya di rumah sakit dapat disebabkan oleh berbagai factor yaitu fisik, kimia, biologi, ergonomi, psikososial, mekanikal, elektrikal, dan limbah. Rumah Sakit (RS) dalam melakukan pengelolaan dan pengendalian potensi bahaya agar terciptanya kondisi RS yang sehat, aman, nyaman, dan selamat bagi sumber daya manusia Rumah Sakit, pasien, pendamping pasien, pengunjung, maupun lingkungan Rumah Sakit, maka perlu penerapan Sistem Manajemen Keselamatan dan Kesehatan Kerja Rumah Sakit (Kementerian Kesehatan RI, 2016).

Kesehatan dan Keselamatan Kerja (K3) merupakan sebuah upaya dalam rangka menjamin keutuhan dan kesempurnaan baik jasmani maupun rohani tenaga kerja, hasil karya dan budayanya menuju masyarakat makmur dan sejahtera. Tujuan diberlakukan K3 adalah agar pekerja memperoleh derajat kesehatan yang tinggi, baik dari segi fisik, mental, maupun social dengan berbagai usaha yang dilakukan. Usaha tersebut meliputi preventif dan kuratif terhadap penyakit maupun gangguan kesehatan yang diakibatkan faktor-faktor pekerjaan dan lingkungan kerja, serta terhadap penyakit-penyakit umum (Redjeki, 2016). Sehingga penerapan K3 merupakan salah satu standard pelayanan yang perlu diperhatikan oleh seluruh aspek yang ada di RS.

Kesehatan dan keselamatan kerja dalam dunia kerja merupakan salah satu isu yang penting saat ini. Data dari International Labour Organization (ILO) menunjukkan bahwa rata-rata 6.000 orang meninggal dunia setiap harinya, hal ini setara dengan2,2 juta orang per tahun akibat kecelakaan maupun sakit berhubungan dengan pekerjaan (Rahayuningsih \& 
Hariyono, 2011). Salah satu permasalahan yang sering dijumpai di RS adalah infeksi nosokomial. Infeksi nosokomial merupakan infeksi yang sering dijumpai dan infeksi ini muncul saat pasien dalam perawatan medis di RS atau fasilitas kesehatan lainnya dan tidak dijumpai pada sebelum dirawat. Infeksi ini dapat terjadi selama pemberian pelayanan kesehatan bahkan setelah pasien keluar, infeksi akibat kerja tenaga kesehatan, dan infeksi ini meliputi infeksi central line, infeksi saluran urinaria, pneumonia, dan infeksi pada area operasi (Khan et al., 2017). Perawat sebagai tenaga kesehatan yang banyak memberikan asuhan kepada pasien memiliki risiko tinggi terkena infeksi nosokomial.

Penerapan Kesehatan dan Keselamatan Kerja di ruang lingkup RS memang sangat diperlukan dan dilakukan oleh seluruh sumber daya manusia yang ada di RS, termasuk perawat. Hasil penelitian menunjukkan bahwa penerapan K3 di Rumah Sakit sangat diperlukan dan merupakan kewajiban sebagai salah satu penilaian akreditasi Rumah Sakit (Ibrahim et al., 2017). Dalam mencapai keberhasilan dalam memberikan asuhan keperawatan kepada pasien, perawat perlu patuh dalam menerapkan K3 selama memberikan asuhan. Sehingga, penulis tertarik untuk mengetahui lebih mengenai penerapan konsep Kesehatan dan Keselamatan Kerja oleh perawat di RS.

\section{Metode}

Metode yang digunakan adalah dengan menggunakan penelitian kuantitatif yang telah dilakukan oleh peneliti dari Indonesia. Sumber jurnal maupun artikel yang digunakan adalah sumber yang terpercaya, dimana pencarian menggunakan electronic database yaitu Google Scholar, jurnal yang digunakan dilengkapi dengan identitas yang lengkap berupa volume dengan tahun terbit 2012-20, serta tersedia full text.

Artikel dan jurnal yang telah diperoleh akan digunakan sebagai hasil dan akan dibahas dalam literature ini. Berdasarkan artikel dan jurnal yang digunakan, maka dapat diketahui gambaran penerapan konsep keselamatan dan Kesehatan Kerja di rumah sakit oleh perawat.

\section{Hasil}

Hasil yang didapatkan oleh penulis adalah penerapan Kesehatan dan Keselamatan Kerja oleh perawat di RS sudah cukup. Penerapan K3 di RS merupakan sebuah kewajiban yang harus dilakukan oleh semua sumber daya manusia, termasuk perawat. Salah satu pelayanan yang dilakukan di RS adalah Perawatan Rawat Inap, dimana perawatan ini merupakan salah satu pelayanan kesehatan yang dapat diakses oleh pasien yang 
membutuhkan perawatan intensif. Keterlibatan dari seluruh tenaga kesehatan dalam memberikan perawatan harus mengacu kepada keselamatan pasien dan keselamatan petugas kesehatan, karena apabila lalai dapat menyebabkan cedera langsung kepada pasien dan perugas kesehatan dan berpengaruh terhadap kualitas dan nilai rumah sakit serta standar pelayanan yang harus dipenuhi (Herawati, 2015).

Penerapan K3 di RS dipengaruhi oleh berbagai faktor. Hasil penelitian yang dilakukan oleh Tukatman et al., (2015) menunjukkan terdapat 3 faktor yaitu faktorp redisposing, enabling, reinforcing, dan core-care. Faktor predisposing terdiri dari pengetahuan, sikap, kepercayaan, dan nilai, dimana factor ini yang paling mempengaruhi terhadap Kesehatan dan Keselamatan Kerja di RS. Indikator predisposing yang paling mempengaruhi adalah kepercayaan. Faktor reinforcing serta factor core-care kurang dominan mempengaruhi kesehatan dan keselamatan kerja pada perawat dalam memberikan pelayanan kepada pasien. Faktor enabling memiliki hubungan dalam penerapan K3 di RS, dimana indicator yang paling mempengaruhi adalah aturan.

Kesehatan dan keselamatan kerja dalam penerapan standard pelayanan kesehatan dinilai dari berbagai aspek atau variabel. Hasil penelitian yang dilakukan oleh Octavia et al., (2018) di Rumah Sakit Umum Dr.Wahidin Sudiro Husodo menunjukkan hasil dimana criteria dalam penerapan kesehatan kerja yang memenuhi syarat terdapat 3 variabel (30\%), cukup memenuhi syarat terdapat 4 variabel (40\%), kriteria kurang memenuhi syarat terdapat 3 variabel (30\%). Variabel yang dikatakan cukup meliputi pemeriksaan kesehatan berkala, pengobatan dan perawatan bagi penderita yang sakit, pemantauan lingkungan kerja dan ergonomi dan evaluasi pencatatan dan pelaporan kepada Direktur Rumah Sakit. Variabel yang dikatakan kurang memenuhi syarat meliputi pemeriksaan kesehatan khusus, pemeriksaan kesehatan sebelum bekerja, dan kegiatan surveilans.

Hasil penelitian pada aspek keselamatan kerja penerapan pelayanan keselamatan kerja yang diterima oleh perawat IGD terdapat 8 variabel (80\%) telah memenuhi syarat,terdapat 1 variabel (10\%) cukup memenuhi syarat dan terdapat 1 variabel (10\%) kurangmemenuhisyarat.Variabel yang cukup memenuhi yaitu evaluasi pencatatan dan laporan kepada direktur RS. Variabel yang kurang memenuhi syarat yaitu penyesuaian terhadap peralatan kerja sumber daya manusia (Octavia et al., 2018).

Hasil penelitian yang dilakukan di RS Aceh menunjukkan bahwa sebagian besar perawat pelaksana memiliki perilaku yang baik dalam penerapan manajemen Kesehatan dan Keselamatan Kerja (K3), dilihat dari faktor internal (52.5\%) maupun factor eksternal (58.8\%) 
(Nazirah \& Yuswardi, 2017). Hasil penelitian yang menunjukkanfaktor yang mempengaruhi kepatuhan perawat di RS Pemerintah Yogyakarta terhadap kewaspadaan standard meliputi motivasi dan pengalaman kerja, dimana faktor yang paling dominan mempengaruhi kewaspadaan standard sebagai penerapan K3 yaitu motivasi (Sagita, 2019).

\section{Pembahasan}

Rumah Sakit (RS) menurut Kementerian Kesehatan RI (2016 )dalam mengelola dan mengendalikan potensi bahaya bagi sumber daya manusia Rumah Sakit, pasien, pendamping pasien, pengunjung, maupun lingkungan Rumah Sakit, maka perlu penerapan Sistem Manajemen Keselamatan dan Kesehatan Kerja Rumah Sakit. Sehingga Kesehatan dan Keselamatan Kerja dalam dunia kerja, khusunya di RS merupakan salah satu isu yang penting saat ini. Infeksi nosokomial merupakan salah satu permasalahan yang sering dijumpai di RS. Infeksi nosokomial merupakan infeksi yang sering dijumpai dan infeksi ini muncul saat pasien dalam perawatan medis di RS atau fasilitas kesehatan lainnya dan tidakdijumpai pada sebelum dirawat. Infeksi ini dapat terjadi selama pemberianpelayanan kesehatan bahkan setelah pasien keluar, infeksi akibat kerja tenaga kesehatan, dan infeksi ini meliputi infeksi central line, infeksi saluran urinaria, pneumonia, dan infeksi pada area operasi (Khan et al., 2017). Perawat sebagai tenaga kesehatan yang banyak memberikan asuhan kepada pasien memiliki risiko tinggi terkena infeksi nosokomial.

Hasil penelitian menunjukkan bahwa penerapan K3 di Rumah Sakit sangat diperlukan dan merupakan kewajiban sebagai salah satu penilaian akreditasi Rumah Sakit (Ibrahim et $a l .$, 2017). Dalam mencapai keberhasilan dalam memberikan asuhan keperawatan kepada pasien, perawat perlu patuh dalam menerapkan K3 selama memberikan asuhan keperawatan bagi pasien.

Penerapan K3 di RS tentu dipengaruhi oleh berbagai faktor. Hasil penelitian yang dilakukan oleh Tukatman et al., (2015) menunjukkan terdapat 3 faktor yaitu factor predisposing, enabling, reinforcing, dan core-care. Faktor predisposing terdiri dari pengetahuan, sikap, kepercayaan, dan nilai, dimana factor ini yang paling mempengaruhi terhadap Kesehatan dan Keselamatan Kerja di RS. Indikator predisposing yang paling mempengaruhi adalah kepercayaan. Hal ini disebabkan karena kepercayaan adalah keyakinan terhadap sesuatu dan ini bersifat abstrak. Serupa dengan agama, manusia percaya dan yakin bahwa ada kiamat meskipun belum sampai di titik itu sehingga manusia hidup dengan aturan 
yang ada di dalam agama yang dianut dengan usaha terbaik untuk menghadapi haltersebut. Sehingga kepercayaan ini yang mendasari perawat untuk menerapkan Kesehatan dan Keselamatan Kerja di RS dalam memberikan asuhan keperawatan kepada pasien.

Faktor reinforcing ialah factor disaat petugas K3 di RS, dalam hal ini perawat dalam memberikan contoh bagi tenaga kesehatan lainnya. Hal ini kurang mempengaruhi perilaku perawat dalam menerapkan konsep K3 di RS, hal ini mungkin disebabkan oleh petugas yang bertanggung jawab kurang maksimal dalam melaksanakan tugas K3 di RS akibat sebagai tugas rangkap. Karena apabila dilaksanakan dengan kesadaran diri sendiri sebagai tenaga kesehatan, maka factor reinforcing kurang berarti sehingga factor ini tidak berpengaruh terhadap penerapan konsep K3 di RS.

Faktor enabling memiliki hubungan dalam penerapan K3 di RS, dimana indikator yang paling mempengaruhi adalah aturan. Hal ini disebabkan karena pada dasarnya perilaku seseorang dipengaruhi oleh berbagai aturan yang ada di lingkungannya. Kebiasaan perawat dalam menaati aturan ini menjadikan perawat menerapkan konsep K3 di RS dengan baik dan menghindari sanksi dari aturan yang telah disusun apabila melanggar. Faktor core-care kurang dominan mempengaruhi kesehatan dan keselamatan kerja pada perawat dalam memberikan pelayanan kepada pasien. Hal ini dipengaruhi oleh kelemahan instrumen yang digunakan dalam penelitian ini, sehingga diperlukan penelitian lebih lanjut.

Penerapan Kesehatan dan Keselamatan Kerja dalam penerapan standard pelayanan kesehatan khususnya di RS akan dinilai dari berbagai aspek atau variabel. Hasil penelitian yang dilakukan oleh Octavia et al., (2018) di Rumah Sakit Umum Dr.Wahidin Sudiro Husodo menunjukkan hasil dimana criteria dalam penerapan kesehatan kerja yang memenuhi syarat terdapat 3 variabel (30\%), cukup memenuhi syarat terdapat 4 variabel (40\%), criteria kurang memenuhi syarat terdapat 3 variabel (30\%). Sehingga dapat dikatakan bahwa penerapan Kesehatan Kerja di RS oleh perawat perlu dilakukan pembenahan guna memaksimalkan pemberian asuhan keperawatan kepada pasien.

Hasil penelitian pada penerapan pelayanan Keselamatan Kerja yang diterima oleh perawat IGD pada penelitian yang sama menunjukkan 8 variabel $(80 \%)$ telah memenuhi syarat, terdapat 1 variabel $(10 \%)$ cukup memenuhi syarat dan terdapat 1 variabel $(10 \%)$ kurang memenuhi syarat. Variabel yang cukup memenuhi yaitu evaluasi pencatatan dan laporan kepada direktur RS. Variabel yang kurang memenuhi syarat yaitu penyesuaian terhadap peralatan kerja sumber daya manusia (Octavia et al., 2018).Sehingga dapat disimpulkan bahwa penerapan Keselamatan Kerja oleh perawat sudah baik dalam 
memberikan asuhan keperawatan kepada pasien dan terus ditingkatkan usahanya agar semakin baik dalam penerapannya.

Perilaku perawat dalam menerapkan konsep Kesehatan dan Keselamatan Kerja di RS cukup baik. Hal ini didukung dengan hasil penelitian yang dilakukan Nazirah dan Yuswardi (2017) di RS Aceh menunjukkan sebagian besar perawat pelaksana memiliki perilaku yang baik dalam penerapan Kesehatan dan Keselamatan Kerja (K3). Hal ini dapat ditinjau dari faktor internal (52.5\%) maupun factor eksternal (58.8\%). Berbagai faktor yang mempengaruhi perilaku perawat ditinjau dari faktor internal berada pada kategori baik yaitu persepsi. Persepsi adalah sebuah proses dalam mencari informasi yang dilakukan oleh perawat sebelum melakukan suatu tindakan. Persepsi perawat tentang K3 menunjukkan bagaimana perawat mampu mencari tahu tentang pentingnya $\mathrm{K} 3$ baik melalui SOP, leaflet, brosur yang disediakan di ruangan maupun media informasi lainnya. Perawat juga dituntut dapat memahami bagaimana cara pencegahan kecelakaan serta penanganan yang dapat dilakukan apabila kecelakaan terjadi. Pemahaman tersebut akan menimbulkan persepsi yang baik dalam diri perawat tentang $\mathrm{K} 3$ sehingga hal ini akan meningkatkan perilakunya dalam menjaga keselamatan.

Sikap perawat mempengaruhi perilaku perawat ditinjau dari segi faktor internal (Notoadmodjo, 2010). Sebagai perawat, penerapan konsep K3 harus memiliki sikap yang sesuai dengan nilai-nilai kesehatan dimana seluruh nilai positif yang ada dalam diri seorang perawat dapat menjadi factor pendorong perilaku sehat dan menjadi upaya dalam meningkatkan kesehatan dan keselamatan selama bekerja.

Faktor eksternal yang dapat mempengaruhi ialah pengalaman perawat dapat dilihat dari berbagai aspek. Salah satunya adalah masa kerja perawat. Apabila semakin lama masa kerja perawat, maka pengalaman yang dimiliki juga semakin meningkat sehingga perilakunya dalam menjaga keselamatan dirinya juga menjadi lebih baik. Selain itu pengalaman juga dapat diperoleh dari berbagai sosialisasi maupun pelatihan tentang K3 yang dilakukan oleh pihak rumah sakit. Faktor selanjutnya yang ikut berperan dalam perubahan perilaku perawat yaitu tersedianya fasilitas yang mendukung sesuai dengan standar yang telah ditentukan.

Hasil penelitian yang menunjukkan faktor yang mempengaruhi kepatuhan perawat di RS Pemerintah Yogyakarta terhadap kewaspadaan standard meliputi motivasi dan pengalaman kerja, dimana faktor yang paling dominan mempengaruhi kewaspadaan standard sebagai penerapan K3 yaitu motivasi (Sagita, 2019). Motivasi dan pengalaman kerja mempengaruhi kepatuhan perawat dalam melaksanakan kepatuhan penerapan konsep Keselamatan dan Kesehatan Kerja. Selan dengan hasil penelitian bahwa seseorang 
termotivasi dengan baik agar mencapai tujuan dari organisasi. Apabila seseorang semakin termotivasi maka akan lebih berkomitmen dan dapat mengidentifikasi peran di organisasi tersebut. Peran pimpinan dalam memberikan motivasi kepada pekerja sangat dibutuhkan terkait tujuan bersama dan insentif (Shanks, 2012 dalam Burton, 2012).

Faktor lain yang mempengaruhi kepatuhan perawat terhadap kewaspadaan standard yaitu persepsi kelengkapan sarana prasarana, persepsi kemampuan diri, peer review komitmen dari system manajemen, informasi, kepercayaan, nilai, kemampuan kognitif, tipe RS, ketersediaan box benda tajam, kepemimpinan serta supervisi.

\section{Kesimpulan}

Penerapan Kesehatan dan Keselamatan di RS oleh perawat merupakan sebuah hal yang sangat penting. Hal ini disebabkan oleh waktu yang dibutuhkan oleh perawat lebih banyak diberikan untuk melakukan asuhan keperawatan kepada pasien yang sedang menjalani perawatan medis. Pengoptimalan dalam penerapan K3 di RS dapat meningkatkan standard pelayanan kepada pasien, dimana hal ini juga akan berpengaruh terhadap akreditasi dari rumah sakit.

Berdasarkan hasil telaah literatur, dapat disimpulkan bahwa perilaku perawat dalam penerapan konsep K3 di RS sudah cukup dan baik. Terdapat beberapa aspek yang dilihat dari kesehatan kerja dan keselamatan kerja di RS, dimana hasil yang ditunjukkan berada dalam kategori cukup dan baik. Faktor-faktor yang mempengaruhi dalam penerapan K3 di RS perlu diperhatikan, baik internal maupun eksternal agar penerapan oleh perawat semakin baik, sehingga angka kejadian infeksi nososkomial maupun angka kecelakaan kerja di RS mengalami penurunan dan pelayanan perawatan kepada pasien semakin baik dan optimal. 


\section{DAFTAR PUSTAKA}

Burton, K., (2012). A study of motivation: how to get your employees moving. Thesis: Indiana University.

Herawati, Y. T. (2015). Budaya Keselamatan Pasien Di Ruang Rawat Inap Rumah Sakit X Kabupaten Jember. Jurnal IKESMA, 11(1), 52-60.

Ibrahim, H., Damayati, D. S., \& Amansyah, M. (2017). Gambaran Penerapan Standar Manajemen Keselamatan dan Kesehatan Kerja Rumah Sakit di Rumah Sakit Umum Daerah Haji Makassar. Al-Sihah : Public Health Science Journal, 9(2), 160-173.

Khan, H. A., Baig, F. K., \& Mehboob, R. (2017). Nosocomial infections: Epidemiology, prevention, control and surveillance. Asian Pacific Journal of Tropical Biomedicine, 7(5), 478-482. https://doi.org/10.1016/j.apjtb.2017.01.019

Nazirah, R., \& Yuswardi. (2017). PERILAKU PERAWAT DALAM PENERAPAN MANAJEMEN KESEHATAN DAN KESELAMATAN KERJA (K3) DI ACEH. Idea Nursing Journal, 8(3), 1-6.

Octavia, W. R., Nerawati, A. . D., \& Sari, E. (2018). PENERAPAN PELAYANAN KESEHATAN DAN KESELAMATAN KERJA PADA PERAWAT IGD RUMAH SAKIT UMUM DR.WAHIDIN SUDIRO HUSODO MOJOKERTO TAHUN 2017. Gema Kesehatan Lingkungan, 16(1), 101-109.

Notoatmodjo, S. (2010). Promosi Kesehatan Teori Dan Aplikasinya. Jakarta: RinekaCipta.

PERATURAN MENTERI KESEHATAN REPUBLIK INDONESIA NOMOR 66 TAHUN 2016 TENTANG KESELAMATAN DAN KESEHATAN KERJA RUMAH SAKIT, 1 (2016).

http://kesjaor.kemkes.go.id/documents/PMK_No._66_ttg_Keselamatan_dan_Kesehatan _Kerja_Rumah_Sakit_.pdf

Rahayuningsih, P. W., \& Hariyono, W. (2011). Penerapan Manajemen Keselamatan Dan Kesehatan Kerja (Mk3) Di Instalasi Gawat Darurat Rsu Pku Muhammadiyah Yogyakarta. Jurnal Kesehatan Masyarakat (Journal of Public Health), 5(1), 25-33. https://doi.org/10.12928/kesmas.v5i1.1084

Redjeki, S. (2016). Kesehatan dan Keselamatan kerja. BPPSDMK Kementerian Kesehatan RI. http://bppsdmk.kemkes.go.id/pusdiksdmk/wp-content/uploads/2017/08/Kesehatan- 
dan-Keselamatan-Kerja-Komprehensif.pdf

Sagita, R. W. (2019). Factors Affecting Nurses' Compliance in Implementing Standard Precautions in Government Hospital in Yogyakarta. Indonesian Contemporary Nursing Journal (ICON Journal), 3(2), 1. https://doi.org/10.20956/icon.v3i2.4972

Simamora, R. H. (2011). ROLE CONFLICT OF NURSE RELATIONSHIP WITH PERFORMANCE IN THE EMERGENCY UNIT OF HOSPITALS RSD DR. SOEBANDI JEMBER. The Malaysian Journal of Nursing, 3(2), 23-32.

Tukatman, Sulistiawati, Purwaningsih, \& Nursalam. (2015). Analisis Keselamatan dan Kesehatan Kerja Perawat dalam Penanganan Pasien di Rumah Sakit Benyamin Guluh Kabupaten Kolaka. Ners, 10(2), 343-347.

World Health Organization. (2015). Comprehensive Safe Hospital Framework. In Who. 